\title{
Precis of When Truth Gives Out
}

\section{Citation}

Richard, Mark. 2012. Precis of when truth gives out. Philosophical Studies 160(3): 441-444.

\section{Published Version}

dx.doi.org/10.1007/s11098-011-9792-4

\section{Permanent link}

http://nrs.harvard.edu/urn-3:HUL.InstRepos:10735583

\section{Terms of Use}

This article was downloaded from Harvard University's DASH repository, and is made available under the terms and conditions applicable to Open Access Policy Articles, as set forth at http:// nrs.harvard.edu/urn-3:HUL.InstRepos:dash.current.terms-of-use\#OAP

\section{Share Your Story}

The Harvard community has made this article openly available.

Please share how this access benefits you. Submit a story.

\section{Accessibility}




\section{Precis of When Truth Gives Out}

Mainstream accounts of meaning have either truth conditional semantics or the assignment of truth bearing propositions to sentences as their primary goal. When Truth Gives Out (WT, henceforth) argues that while giving truth conditions and assigning truth bearers to sentences and mental states plays a role in an account of meaning, important aspects of meaning are not explained in such terms. It argues further that when we invoke truth conditions or truth bearers in an account of meaning, we must employ a non-standard notion of truth, on which truth is relative to both a possible world and something contributed by human interests $-\mathrm{a}$ perspective, a set of standards for applying our concepts, or the like.

WT's first three chapters look at some of the ways in which the performative aspects of our talk -what we do with our words -bear on whether and when our talk should or can be evaluated in terms of truth. Chapter 1 argues that talk involving racial slurs may be truth valueless as a result of its performative dimension. The chapter begins with a puzzle: On the one hand, racial epithets seem to have clear application conditions. It is a linguistic mistake to call a Frenchman a 'limey.' This makes it seem that slurs must be true of their targets. On the other hand, if someone slurs in saying something --a bigot says 'a [slur] lives in that building' --we do not want to say that what was said is true. For if I think what the bigot said is true, I think that a [slur] lives in the building. Most of us do not believe that sort of thing.

To resolve the puzzle, we need to accept that the performative and expressive aspects of slurring are just as much components of the "sense" of 
the slur as is the fact that the slur is used to classify a certain group. Because of this, thinking of someone as a *, * a slur on people of kind $\mathrm{K}$, is thinking of him in a different way than thinking of him as a K. Furthermore, the performative and expressive aspects of a slur involve representation, but represent differently than other words. For one way to represent someone as contemptible is to show contempt for them, just as one way to represent something as deserving of fear is to be afraid of it. Thus, slurring thoughts not only express contempt, they represent their targets through such contempt as contemptible because of their ethnicity or race. They therefore misrepresent them, as no one is contemptible for that reason. So these thoughts are not true. But they are not therefore false. If they were, we could adjust the mistake made in an utterance of if Bob married $a^{*}$, he's unhappy simply by pointing out that though Bob married a *, he’s quite happy. But we can’t do this, because making this last claim is still displaying contempt and thus (mis) representing. The upshot is that slurring speech, though expressing beliefs and (mis)representing the world, is simply not truth evaluable. It involves error and must therefore be rejected. But to say this is not to say that what the racist says is false.

Slurs can sometimes be used without the user being liable to censure. This raises the question of whether the evaluative and performative elements associated with slurs are essential to their meanings and to the thoughts expressed with them. The same question arises for other "thick terms": Do we change such a term's meaning when we succeed in using it without taint of its conventional evaluative dimension? Chapter 1 essays the beginning of an answer to such questions, defending a view of word meaning and concept individuation on which whether something is part of a concept or of a word's meaning depends as much on contextual and social factors operative 
in the context in which questions about the meaning or concept are asked, as it does on context independent factors.

Chapter 2 begins with the following puzzle. Sometimes, when we talk about talk -when, for example, we talk about paradoxical sentences such as the liar -we seem to "get things right", but our getting it right can't be a matter of our saying something true. A liar sentence is, of course, not true -that's something we can prove, and we thus know. Something similar holds of the claim that applications of vague predicates to their borderline cases are without truth value. If Jo is a borderline case of baldness, it seems it's not true that he's bald, and not true that he's not. And it seems to pretty much everyone that Jo's bald iff it's true that he's bald. But contradiction ensues if all these things are true.

Chapters 2 and 3 develop the idea that there are more ways to "get things right" than simply by asserting something -that is, by committing to a claim's truth. One can, for example, deny the claim that the liar is true, where denial is understood as sui generis and not reducible to assertion of a negation; denying $\mathrm{p}$ is apt iff $\mathrm{p}$ is not true -that is, false or without truth value. ${ }^{1}$ If we see connectives like 'not' as sometimes contributing to the sense of what one says with a sentence, sometimes acting as "force indicators" -conveying information about the act being performed -we can make sense of the idea that someone could "get it right" without speaking the truth.

Frege famously objected to this idea; Geach famously extended Frege's objection to the view that (for example) normative sentences are not in the business of enabling assertion. Chapters 2 and 3 of WT make three

\footnotetext{
${ }^{1}$ As such, denial of $\mathrm{p}$ is not assertion of p's negation, since the latter is not apt when $\mathrm{p}$ is truth valueless.
} 
points. (1) One kind of expressivist semantics has a straightforward response to the Frege-Geach problem; (2) this semantics helps explain how we can correctly say that a sentence or claim is neither true nor false, and thus affords some insight into vagueness and semantic paradox; (3) it also provides a response to worries that expressivist and emotivist accounts of evaluative language can't give a coherent account of negation, disjunction, and the like.

The semantics is based on three assumptions. (1) Simple sentences are conventional means for expressing mental attitudes (like belief, valuing, and being (morally) tolerant) and performing speech acts (like assertion and denial). (2) These mental states and speech acts involve commitments. Belief and assertion commit one to the truth of what is believed; valuing $\mathrm{X}$ commits one to X's being valuable. These commitments, in turn, have aptness conditions: commitment to p's truth is apt provided p is true; valuing $\mathrm{x}$ is apt provided $\mathrm{x}$ is valuable; toleration is apt provided what is tolerated is tolerable. This means that associated with the simplest sentences of our language are a mental attitude, an associated commitment, and the aptness conditions of the commitment. ${ }^{2}$ (3) For semantic purposes, we may blur the distinction between a commitment and its aptness conditions. An expressivist semantics ought compositionally assign commitments represented in terms of their aptness conditions to sentences; in particular, it should treat sentence compounding devices as expressions whose meanings map commitments-represented-via-their-aptness-conditions to commitments. In doing this, the semantics makes clear how sentences are related to speech acts and mental states: a sentence is a conventional means

\footnotetext{
${ }^{2}$ Of course the commitment associated with a sentence may vary across contexts if the sentence has contextually sensitive vocabulary. I ignore this sort of thing when sensible.
} 
for expressing a mental state $\mathrm{S}$ or performing act A provided that the characteristic commitment of S or A is the semantic value of the sentence. Doing this and defining validity as preservation of commitments allows us to respond to Frege and Geach.

The material in Chapters 2 and 3 seems to me relevant to questions about how much of the semantics of a language one can do in the language itself. In an appendix, I discuss an extension of the language of Chapter 2 to one which contains its own Kripkean truth predicate, as well as a predicate which characterizes appropriateness of the commitments that can be incurred by using the language's sentences.

The second half of the book takes up relativism about truth and the status of opinions about "matters of taste”. By relativism, I mean the view that what we say or think is at least sometimes true only relative to something determined by the interests or standards of thinkers. One goal of Chapter 4 is to show that pedestrian facts about when we judge people to disagree, along with widely accepted views about how the interests of speakers effect the interpretations of their words, entail relativism. A second goal is to argue that relativism, in and of itself, is a relatively benign view accepting it, even as true of the majority of claims we make, does not require that we allow that any opinion is as good as any other, or that when a claim is "true for me, false for you", there cannot be reasoned argument between us, or even good reason for one of us to come around to the other's opinion. We do not have to embrace an "absolute" notion of truth simply because we want to insist that some views are wildly unreasonable, or that there is often or even usually a best way to think about a matter.

Pretty much everyone allows that gradable adjective (such as 'rich', 'red', 'rotund', and 'religious') vary in extension across different contexts 
with the interests and purposes of conversants. David Lewis famously and convincingly argued that conversational "rules" and processes (such as “accommodation”) demand such variation. But we very often take people in different contexts, contexts with different standards for applying such adjectives, to have a genuine disagreement -as when, say, Naomi and her blue collar friends think the million dollar lottery winner to be rich, Didi and her blue blooded friends think that such a person is obviously not rich. But if they disagree, they are saying the same thing with 'Mary is rich'; if application varies with context, each speaks truly.

After exploring some ways of trying to non-relativistically reconcile these facts and finding them wanting, I sketch a version of relativism which makes sense of them. On it, truth is something a claim sometimes has only relative to the standards conversatants adopt or presuppose. None of the standard charges of incoherence directed at relativism apply to this view it's not self defeating (it is not relatively true), it doesn't entail that there are "true contradictions". And quite plausible views of the nature of concepts ones which ground concept identity (partially) in such things as functional roles, "partial definitions”, or a "core extension” and a prototype structure provide a natural model of thought and meaning on which such relativism is to be expected.

A likely place to look for relative truth, it seems, is in matters of taste. Our detailed conceptions of who is handsome, what is hip, what perverted these typically differ. And at the end of the day, my judgment of who is sexy, hip, or perverted seems to answer to my considered opinions on the matter; likewise for yours. But we nonetheless will argue about whether someone is sexy, whether a certain activity is perverted -we take ourselves 
to disagree, and think the disagreement (sometimes) worth argument. And this sounds like a setting in which genuine relativism might flourish.

Chapter 5 of WT sketches a expressivist alternative to relativist accounts of judgments of taste. It gives an account of an expressivist account of 'faultless disagreement', discusses how to understand ascription of possibility and necessity to taste claims, and offers arguments against contextualist accounts that say we should understand predicates like 'is tasty' as having an implicit 'judge argument', so that (for example) typical uses of 'that is tasty' say what is said by something of the from that is tasty to so and So. 